\title{
The high temperature resistance of a para-aramid fibre-reinforced concrete composite
}

\author{
D. Koňáková, M. Čáchová, K. Polozhiy, E. Vejmelková, \\ M. Keppert \& R. Černý \\ Department of Materials Engineering and Chemistry, \\ Faculty of Civil Engineering, Czech Technical University, \\ Czech Republic
}

\begin{abstract}
This article deals with a para-aramid fibre-reinforced composite based on Portland cement and is exposed to a high temperature loading. The main emphasis is on the residual properties after a temperature loading (of up to $1000^{\circ} \mathrm{C}$ ). Two basic mixtures were designed, the first without para-aramid fibres and the second with them. The studied materials were exposed to three different temperature loadings and then a group of physical characteristics was determined. The designed fibre-reinforced composite could find its application as a material that improves the fire resistance of constructions, for example as boards for tunnel lining, or anywhere where a higher fire hazard or a higher temperature loading is present.

Keywords: para-aramid fibres, concrete, high temperature, residual properties.
\end{abstract}

\section{Introduction}

Concrete and materials based on cement are undoubtedly one of the most used building materials in civil engineering. Concrete has quite a low tensile strength; therefore it has to be reinforced for almost all structures applications. It was proved that utilization of reinforcement should improve not only tensile strength but also other mechanical properties, its durability, fire resistance, etc. Nowadays, the most usual reinforcement is not just a steel bar, but an application of various kinds of fibres becomes common, such as steel fibres [1], carbon 
fibres [2], glass fibres [3], or organic fibres. The development of polymers fibres represents another possibility of concrete reinforcement. In this area, studies of utilization of, for example polypropylene fibres [4] or hybrid PVC fibres [5] were carried out. This article also deals with one kind of polymer fibres para-aramid fibres. As it was proved by Sumid [6], this type of fibre has excellent properties and it is a suitable material for concrete reinforcement.

The aim of this study is to design a material with appropriate fire resistance properties for structures with a higher fire hazard (such as boards for tunnel lining) or as a face panel for improving thermal resistance. In the first step the composition of the matrix was designed and tested under high temperature conditions (respectively after a high temperature exposure). This matrix, in the main part of this study, should have been upgraded. Since it was proved in previous studies $[2,3,5]$ that fibres can improve thermal resistance, and para-aramid fibres seem to be suitable reinforcing materials (thanks to their adequate properties [7]), the matrix was reinforced by para-aramid fibres. So the main part of this study deals with residual properties of a para-aramid composite material based on cement compared to the same composite material with no reinforcement. The matter of this work is also to find out the influence of para-aramid fibres on residual properties after a thermal loading.

\section{Materials studied}

The studied materials are composite materials based on a cementitious matrix in which the binder was the classic cement CEM I 52.5. As an aggregate, Wollastonit - Casiflux F 125 was utilized because it has high stability at higher temperatures [8]. Another type of employed aggregate was Expancel Microspheres 461 DE 2070 . The other component of the studied composite was Silica fume 940 - US and plasticiser Glenium ACE 40. As it was mentioned in the introduction, the goal of this study is the determination of the influence of para-aramid fibres on the thermal resistance of the cementitious composite. So the difference between the two studied materials is in the content of the polymer fibres. The reference material (CR) has no fibres, while the second material (CF) contains para-aramid fibres. Tawron 1488 - tex $350.6 \mathrm{~mm}$ was used as a fibre filler. In Table 1 the particular composition of the composites mixtures is presented.

Table 1: Mixtures composition [kg m-3].

\begin{tabular}{|l|c|c|}
\hline Component & CR & CF \\
\hline CEM I 52.5 & 1420 & 1420 \\
\hline Wollastonit - Casiflux F 125 & 1070 & 1070 \\
\hline Silica fume 940 - US & 72 & 72 \\
\hline Expancel 461 DE 20 70 & 100 & 100 \\
\hline Glenium ACE40 & 21 & 21 \\
\hline Twaron 1488 - tex 350.6 mm & 0 & 93 \\
\hline water & 1590 & 1680 \\
\hline
\end{tabular}


The production process was as follows. First, all dry components (except for Expancel) were metered into a stable container and homogenized by a rotating stirrer for two minutes. Then, in the case of the composite containing fibres, Tawron was added and followed by two more minutes of homogenization. Then Expancel along with the mixing water and the plasticiser were added. The next step was a final homogenization performed for 3 minutes so that consistency of the casting slurry was achieved. From the fresh mixture experimental boards were prepared, and after 24 hours these boards were autoclaved at $195^{\circ} \mathrm{C}$. Then specific samples for the measurements were made up.

Since the aim of this work was to study composite materials under a high temperature loading, respectively their residual properties, the samples had to be exposed to a high temperature. This was performed in a special electric oven, and the studied materials were pre-treated by three different thermal conditions. Apart from the reference samples (they were not exposed to any temperature loading), composite materials were studied after an exposure of $600^{\circ} \mathrm{C}, 800^{\circ} \mathrm{C}$, and $1000^{\circ} \mathrm{C}$. The composites samples were put into the electric oven with a gradual temperature growth. The desired temperatures $\left(600^{\circ} \mathrm{C}, 800^{\circ} \mathrm{C}\right.$ or $1000^{\circ} \mathrm{C}$ ) were achieved after two hours. The samples were exposed to these temperatures for two more hours. The samples were denoted according to their temperature loading. Thus, the reference composites were labeled as CR-ref, CR600 , CR-800 and CR-1000, while the material containing fibres were marked as CF-ref, CF-600, CF-800 and CF-1000.

\section{Experimental methods}

\subsection{Basic physical properties}

The bulk density, matrix density and open porosity were measured using the vacuum water saturation method [9]. This method is based on weighing samples in different moisture states. Three samples of each type of composites with dimensions of $40 \times 40 \times 40 \mathrm{~mm}$ were used for this measurement. The first measured moisture state was the dried one. To remove physically bounded water, the samples were put into a drying box kept at the temperature of $105^{\circ} \mathrm{C}$. The second state was the saturated one. The samples were put into a desiccator with boiled distilled water and air was evacuated with a vacuum pump. After removing the samples from the desiccator, their mass in the saturated state was determined. Finally, the value necessary for calculating the basic physical properties is the mass of saturated samples under the water, so called the Archimedes mass.

Characterization of a pore structure was determined by the mercury intrusion porosimetry. This method is based on the determination of the external pressure needed to force the mercury into a pore against the opposing force of the liquid's surface tension. The pore size is then calculated from the measured pressure using Washburn's equation. The experiments were carried out using instruments PASCAL 140 and 440 (Thermo Scientific). The range of an applied pressure 
corresponds to the pore radius from $10 \mathrm{~nm}$ to $100 \mu \mathrm{m}$. The size of the specimens is restricted to the volume of approximately $1 \mathrm{~cm}^{3}$.

\subsection{Mechanical properties}

The determination of the bending strength was done using the electromechanical testing device MTS Alliance RT 30. It allows the maximum load of $27.80 \mathrm{kN}$ and the arrangement of experiment was the three-point bending. The rate of loading was $0.04 \mathrm{~mm} / \mathrm{min}$. The values of the bending strength were calculated from the measured force values using the standard physical formulas. Six samples with dimensions of $40 \times 40 \times 160 \mathrm{~mm}$ were used for the determination of the residual bending strength (after a $0^{\circ} \mathrm{C}, 600^{\circ} \mathrm{C}, 800^{\circ} \mathrm{C}$ and $1000^{\circ} \mathrm{C}$ temperature loading).

Measurements of the tensile strength should have been performed by the same device as for the determination of the bending strength. The rate of loading should have been $0.025 \mathrm{~mm} / \mathrm{min}$. However, the measurement could not be performed since all samples were damaged during positioning into the jaws of a tensile machine.

\subsection{Hygric properties}

The liquid water transport was characterized by the water absorption coefficient. Three specimens with dimension of $50 \times 50 \times 25 \mathrm{~mm}$ were water and vapor-proof insulated on four lateral sides and the face side was immersed by 1-2 $\mathrm{mm}$ in water. A constant water level in the tank was achieved by a Mariotte bottle with two capillary tubes. One of them, with an inside diameter $2 \mathrm{~mm}$, was ducked under the water level. The second one, with an inside diameter $5 \mathrm{~mm}$, was above water level. The automatic balance allowed recording the increase of the mass. The water absorption coefficient was determined from the sorptivity plot [10].

The cups method was employed in measurements of water vapor transport parameters [11]. For this measurement three samples with dimensions of $100 \times 100 \times 20 \mathrm{~mm}$ were, similarly to the liquid transport experiment, water and vapor-proof insulated on four lateral sides and then the cups were prepared. In the dry-cup method sealed cups containing silica gel were placed in a controlled climatic chamber with $50 \%$ relative humidity and weighed periodically. For the wet-cup method the sealed cups contained water. The measurements were carried out at $25^{\circ} \mathrm{C}$ over a period of five weeks. The steady state values of the mass gain or mass loss determined by linear regression for the last five readings were used for the determination of water vapor transport properties. The water vapor diffusion resistance factors were calculated from the measured data using the procedure described in [11].

\subsection{Thermal properties}

The last group of measured characteristics is thermal properties. Using the device ISOMET 2104 [12], the thermal conductivity was measured. This commercial 
device applies a dynamic measurement method so that time of measurement reduces to dozens of minutes. The measurement process is based on an analysis of a temperature response of an analyzed material to heat flow impulses. The heat flow is induced in a resistor of a probe by a distributed electric power. The temperature is recorded and evaluated from the polynomial regression.

The thermal conductivity was determined in dependence on the moisture content. Three samples with dimensions of $70 \times 70 \times 70 \mathrm{~mm}$ were employed for the measurement of thermal properties.

\section{Experimental results}

\subsection{Basic physical properties}

In Figure 1 and 2 the results from the water vacuum saturation method are presented. It is obvious that the studied composite materials show quite low bulk densities (in comparison with other cementitious materials). This is caused by Expancel and Wollastonit admixtures in the composition mixture, which result in a decrease of the bulk densities. Wollastonit has a low bulk density, it is $750 \mathrm{~kg}$ $\mathrm{m}^{-3}$ [8]. The Expancel admixture has a greater influence on the basic physical properties. Since the autoclaved temperature is higher than the auto ignition temperature of Expancel (the latter is $170^{\circ} \mathrm{C}$ [13]), Expancel burns out during autoclaved treatment and so the porosity of the composite material decreases. Therefore the bulk density increases. After temperature exposure the basic physical properties are changed in both cases of the studied composites. The residual matrix density grows up with the rising temperature loading; in the case of the reference material it is by about $51 \%$, while in the case of the fibre-reinforced composite it is by about $42 \%$. It corresponds with a material transformation - the hydrated phase is decomposed and more dense anhydrous minerals are formed. Simultaneously the residual open porosity increases considerably. The open porosity of the reference composite increases more than twice, and by adding the para-aramid fibres the growth is slightly less, just one and a half times more. Therefore the residual bulk density goes down. The change after a temperature loading of the bulk density of the reference material is about $12 \%$ and the fibre-reinforced material changed by about $24 \%$. When comparing both composite materials, the difference between the bulk densities of the studied material with no temperature exposure is about $9 \%$. In the case of the matrix densities it is $33 \%$ and the open porosities differ by about $18 \%$, while in the case of the matrix density it was about $9 \%$.

Pore changes are more obvious in Figure 3 where the results from the mercury porosimetry are presented. The pore system can be divided according to the pore size and reaction to the thermal loading. The gel pores (the space between the particles of hydration product) disappear with an increasing temperature because of the dehydration of hydrated products. This phenomenon is connected with a shrinking process, which leads to the growth of capillary pores (the space between the aggregations of hydration product). 


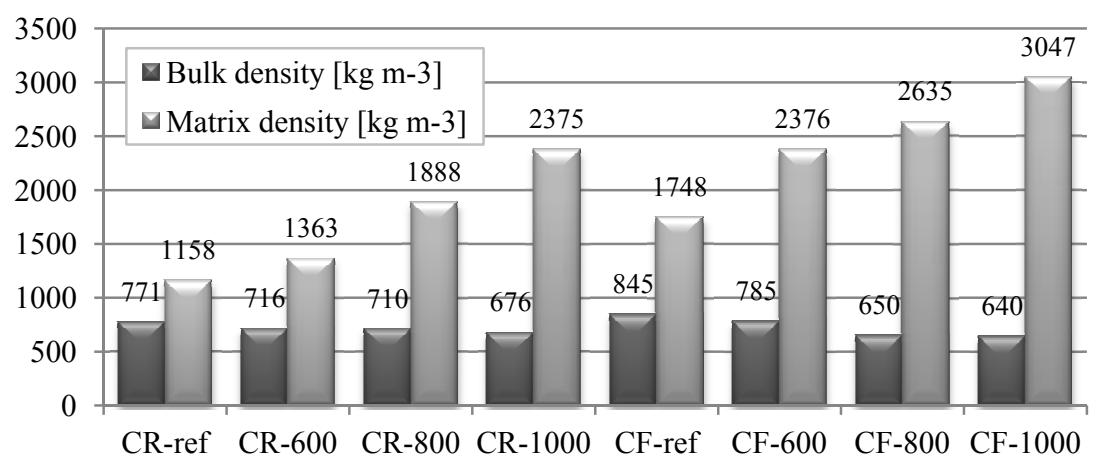

Figure 1: Bulk density and matrix density.

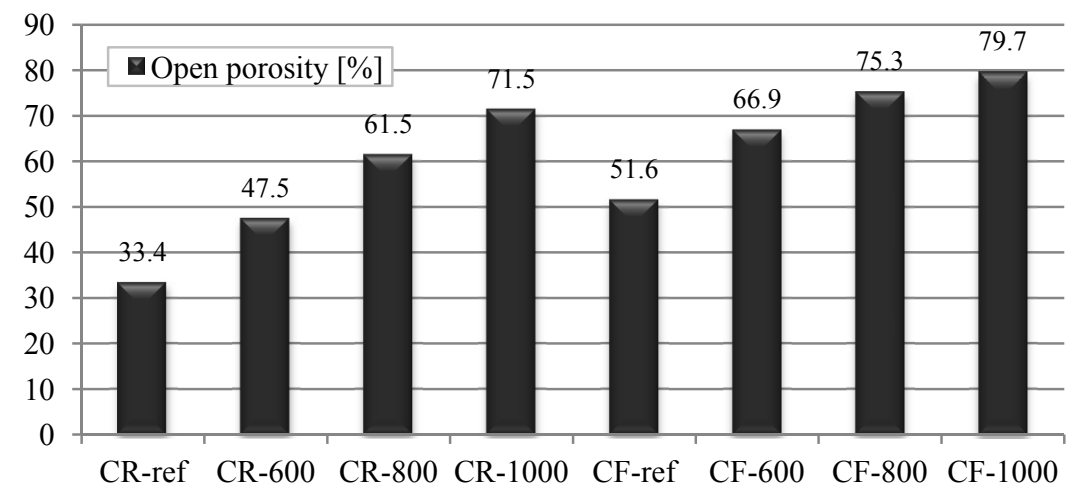

Figure 2: Open porosity.

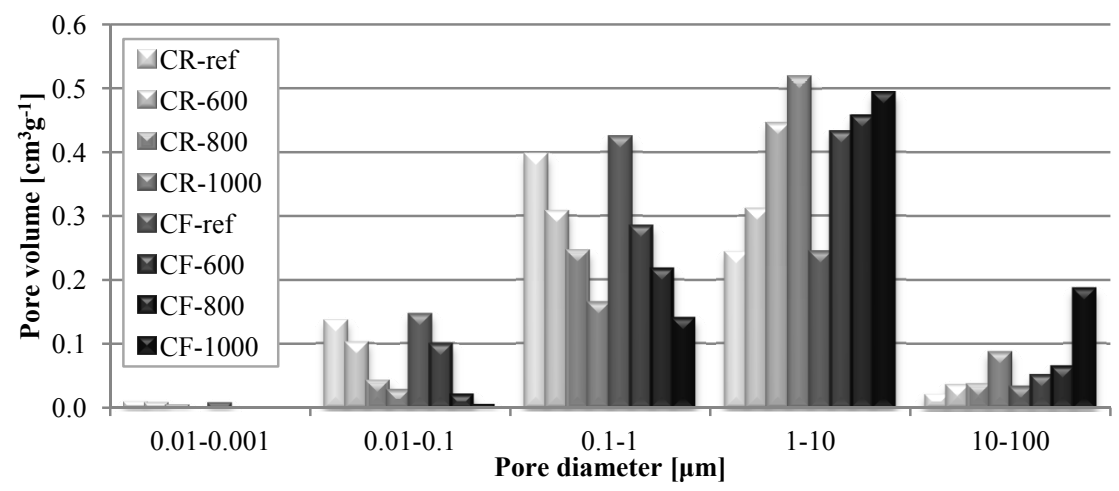

Figure 3: Pore size distribution. 


\subsection{Mechanical properties}

In Figure 4 the decrease of the bending strengths with an increasing temperature exposure is shown, which corresponds with rising open porosity (Figure 2). It is obvious that the para-aramid fibres have positive effect on the bending strength, because the fibre-reinforced composite achieved in the reference state $\left(0^{\circ} \mathrm{C}\right)$ a value of the bending strength that was higher by 34\% than for the material without fibres. This difference decreases with an increasing temperature loading; after $600^{\circ} \mathrm{C}$ the difference between the residual bending strength is about $21 \%$, after $800^{\circ} \mathrm{C}$ it is less than $14 \%$, and this drop continues to almost no difference at the temperature $1000^{\circ} \mathrm{C}$. This result could be predicted because at temperatures higher than $600^{\circ} \mathrm{C}$, thanks to the used Portland cement, matrix is losing its mechanical properties and therefore the fibres have almost no effect on the residual bending strengths.

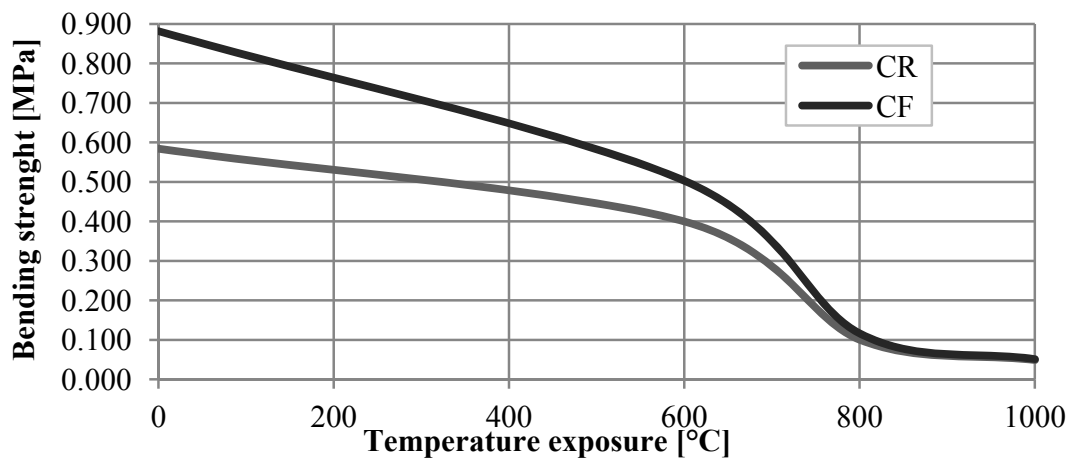

Figure 4: Bending strength.

\subsection{Hygric properties}

Liquid water transport ability is described by the water absorption coefficient whose measured values are presented in Figure 5. The achieved results do correspond with the experimental data of the open porosity (Figure 2). As in the case of the open porosity, the higher the temperature loading the composites are exposed to, the higher the values of the water absorption coefficient materials show. From this measurement it can be predicted that the fibres reinforcing by para-aramid fibres leads to a growth of the water absorption coefficient. The achieved results of the liquid water transport ability differ in the reference state (with no temperature loading) by about $45 \%$ and by about $25 \%$ in the state after the temperature exposure of $1000^{\circ} \mathrm{C}$. 


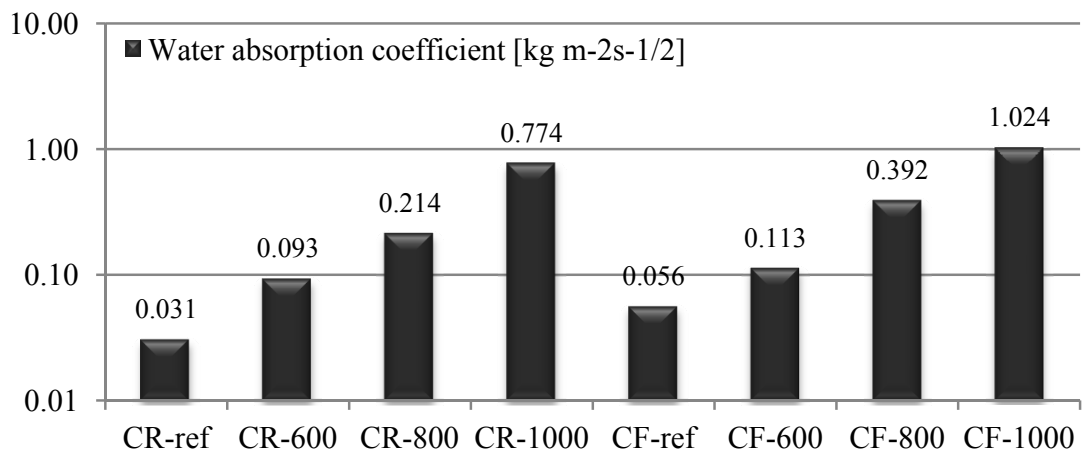

Figure 5: Water absorption coefficient.

The water vapour diffusion resistance factor describes water vapour transport abilities. The cup methods were employed for its determination and the results from this measurement are summarized in Figure 6. The values from dry-cup and wet cup arrangements differ widely, but it is a well-known phenomenon appearing in many previous measurements [14]. It is attributed mostly to the transport of capillary condensed water in the wet-cup arrangement which adds up to the bulk transport of water vapour in the pore system. In comparison of both studied composites, the para-aramid fibre-reinforced material showed a higher ability of the water vapour transport. It is in accordance with porosimetry data (Figure 2), as in the case of the liquid water transport. The difference between the composite materials is in the reference state $26 \%$ in the dry-cup arrangement and $27 \%$ in the wet-cup arrangement. In the residual state after the $1000^{\circ} \mathrm{C}$ loading the values of the water vapour diffusion resistance factor differ by $22 \%$ in the dry-cup and by $23 \%$ in the wet-cup state.

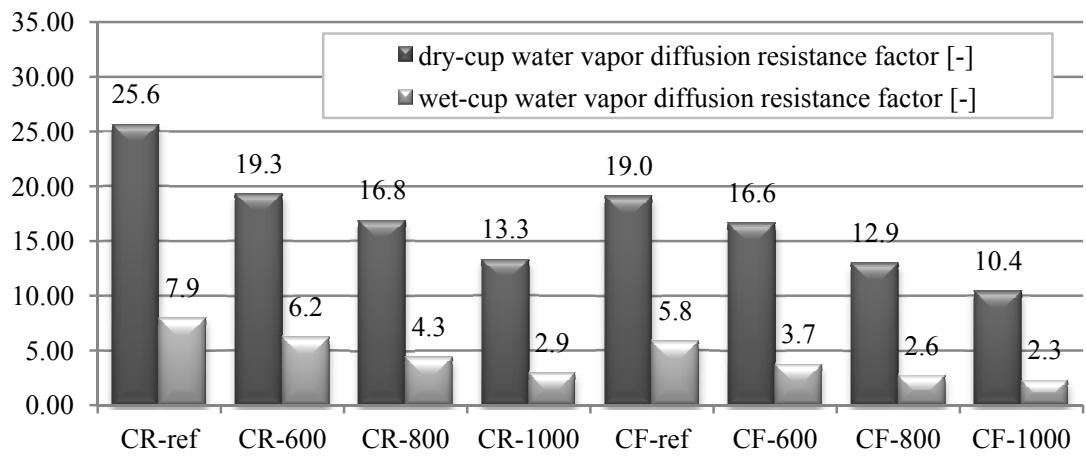

Figure 6: Water vapour diffusion resistance factor. 


\subsection{Thermal properties}

The results achieved from the measurement of the thermal conductivity as depending on the moisture content are presented in Figure 7. It is obvious that as the moisture content grows, the thermal conductivity also increases. This tendency is a common phenomenon caused by different values of the thermal conductivity of water and air. From the achieved results it can be predicted that in the case of these composites the main impact on the thermal conductivity is due to their porosity. The measured data correspond with the results showed in Figure 2. The lowest value of the thermal conductivity was achieved by the reference material without fibres without a temperature loading, while the highest values were achieved by the para-aramid fibre-reinforced composite after a thermal loading of $1000^{\circ} \mathrm{C}$. In comparison of studied materials the one with no fibres reinforcing showed by $20 \%$ lower values in the dry state and by $21 \%$ lower values in the wet state. However, the measured thermal conductivities do not differ much, so it can be deduced that adding para-aramid fibres to the cement based composite does not lead to any major improvement of thermal transport abilities of the final reinforced material, although the progress is obvious.

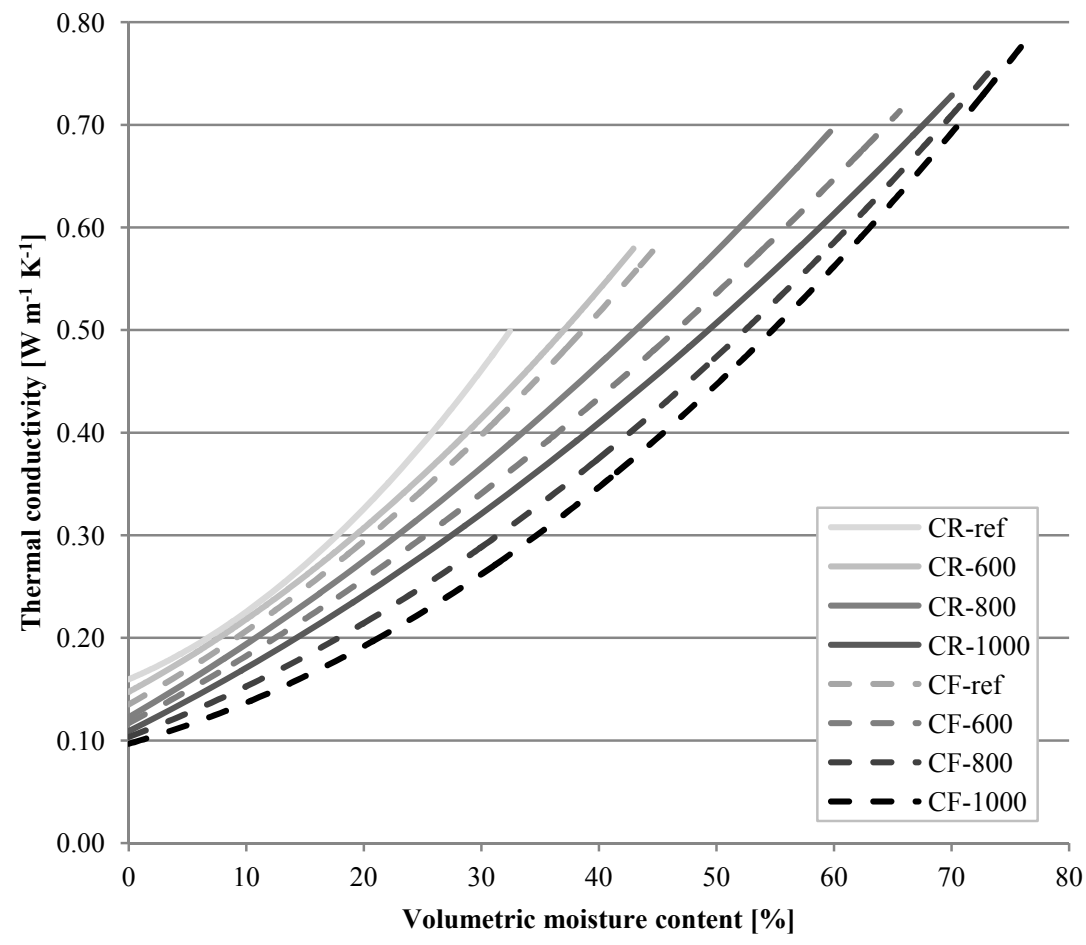

Figure 7: Thermal conductivity. 


\section{Conclusion}

The aim of this study was to improve thermal resistance of cement based composites. As a reference material the matrix composed of cement, Wollastonit, silica fume and Expancel was chosen. The studied material differed from the reference one by a content of para-aramid fibres. So the matter of this article was to determine how these para-aramid fibres influence the behaviour of the composite with a temperature loading.

Thermal resistance was studied owing to the determination of the residual properties of studied materials. The composites were exposed to three different temperature loadings (no temperature treatment, $600^{\circ} \mathrm{C}$ and $1000^{\circ} \mathrm{C}$ ) and then the measurement of several physical properties was performed.

The basic physical properties were studied employing the water vapour saturation methods and mercury porosimetry. Reinforcing by para-aramid fibres leads to an increase in the bulk and matrix density. The same phenomenon occurs for the porosity of the composite material. However, thanks to the para-aramid fibres, the growth of the open porosity with a temperature loading is slowed down.

The bending strength was measured by the classical three-point arrangement. In the case of the mechanical properties utilization of para-aramid fibres leads to improving of bending strength, but the amelioration is considerable up to the $600^{\circ} \mathrm{C}$ since at higher temperature loadings the cementitious matrix significantly loses its mechanical strength.

Water transport abilities grow with an addition of para-aramid fibres. This properties rise in both cases of the water phase in the material. The liquid water transport was determined from the sorptivity plot, while the water vapour transport was measured by the cups method. An increase of the transported water is caused by a growing open porosity. However, the difference between the achieved values in a particular temperature exposure is not major.

Thermal properties were also studied in this article. ISOMET 2104 was employed for the measurement of the thermal conductivity as depending on the moisture content. The composite with a para-aramid fibre reinforcing has slightly improved insulating properties.

The utilization of para-aramid fibres as reinforcing of cement based composite seems to be positive. The main improvement seems to be in the mechanical properties. Yet, the reinforcing leads to minor advantages also in the case of hygric properties as well as in thermal characteristic. So it can be concluded that the designed para-aramid fibre-reinforced, cement based composite can be utilized as a material with better temperature resistance.

\section{Acknowledgement}

This research has been supported in the Czech Republic under project SGS13/165/OHK1/3T/11. 


\section{References}

[1] Jianhua, W., The Study of Steel Fiber Reinforced Concrete Durability Based on Damage Mechanics. Research Journal of Applied Sciences, Engineering and Technology, 7(3), pp. 543-550, 2014.

[2] Vejmelkova, E., Konvalinka, P., Padevet, P., Cerny, R., Effect of high temperatures on mechanical and thermal properties of carbon-fiber reinforced cement composite. Cement Wapno Beton, 13(2), pp. 66-74, 2008.

[3] Vejmelkova, E., Konvalinka, P., Padevet, P., Cerny, R., Thermophysical and Mechanical Properties of Fiber-Reinforced Composite Material Subjected to High Temperatures. Journal of Civil Engineering and Management, 16(3), pp. 395-400, 2010.

[4] Keppert, M., Vejmelkova, E., Svarcova, S., Bezdicka, P., Cerny, R., Microstructural Changes and Residual Properties of Fiber Reinforced Cement Composites Exposed to Elevated Temperatures. Cement Wapno Beton, 17(2), pp. 77-89, 2012.

[5] Vejmelkova, E., Konvalinka, P., Padevet, P., Kopecky, L., Keppert, M., Cerny, R., Mechanical, Hygric, and Thermal Properties of Cement-Based Composite with Hybrid Fiber Reinforcement Subjected to High Temperatures. International Journal of Thermophysics, 30(4), pp. 1310-1322, 2009.

[6] Sumid, A., Reinforcement and Retrofit of Concrete Structures with Aramid Fiber. Proc. of FRP Composites in Civil Engineering, Elsevier Science BV, pp. 273-280, 2001.

[7] Twaron ${ }^{\circledR}$ para-aramid Yarn, Material Safety Data Sheet: http://torchwear.com/pdf/Twaron-MSDS.pdf

[8] Sibelco Specialty Minerals Europe, Technical data - Casiflux: http://www.tecmos.com/carga/empresas/archivos/10648cd5fdcff2d284880 9a5b47fc93f.pdf

[9] Kumaran, M. K., Moisture Diffusivity of Building Materials from Water Absorption Measurements. Journal of Thermal Envelope and Building Science, 22, pp. 349-355, 1999.

[10] Vejmelková, E., Pavlíková, M., Jerman, M., Černý, R., Free Water Intake as Means of Material Characterization. Journal of Building Physics, 33(1), pp. 29-44, 2009.

[11] Roels S, Carmeliet J, Hens H, Adan O, Brocken H, Černý R, Pavlík Z, Hall C, Kumaran K, Pel L, Plagge R. Interlaboratory Comparison of Hygric Properties of Porous Building Materials. Journal of Thermal Envelope and Building Science 2004; 27: 307-325.

[12] Applied Precision - ISOMET. [User manual], Bratislava, 1999.

[13] AkzoNobel, Safety data sheet - EXPANCEL $®$ Microspheres 461 DE20 d70: https://www.b2bcomposites.com/msds/ecc/589136.pdf

[14] Černý R., Rovnaníková P., Transport processes in concrete, Spon Press: London, 2002. 